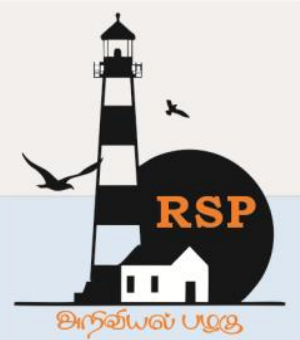

INTERNATIONAL RESEARCH JOURNAL ON ADVANCED SCIENCE HUB

RSP SCIENCE HUB

(The Hub of Research Ideas)

Available online at www.rspsciencehub.com

\title{
Study of tribology behavior of hybrid composites of aluminium matrix using taguchi gray relational analysis system
}

S.Perumal

${ }^{1}$ Assistant Professor, Department of Mechanical Engineering, Karpaga Vinayaga College of Engineering and Technology, Chengalpattu, Tamilnadu, India-603308

perumalpearl@gmail.com ${ }^{1}$

\begin{abstract}
This paper introduces an efficient approach to optimising the tribological characteristics of Hybrid Aluminium Matrix Composites (356-B4Cp-MoS2) and (356-B4Cp-Gr) manufactured by stir casting, with multiple performance characteristics dependent on grey relational study. B4C was kept constant at 6 percent for all two composites in this study (356-6 percent B4C-2 percent MoS2 and 356-6 percent B4C-2 percent $G r$ ) and $G r$ and MoS2 were used at 2 percent wt. Dry sliding wear tests were performed using a standard pin on disc test setup based on Taguchi's orthogonal arrays following a well planned experimental schedule. Considering several performance characteristics: wear rate, basic wear rate and friction coefficient, the input parameters such as sliding speed, sliding distance, load and reinforcement percentages are optimised. From the response table and response graph of the grey relational grade, the optimal levels of input parameters were selected. The meaning of the wear parameters was discovered using ANOVA.
\end{abstract}

Keywords: Hybrid Aluminium matrix composites, Stir casting, Taguchi Design of Experiments, Grey Relational analysis, ANOVA.

\section{Introduction}

As new products, metal matrix composites have emerged as a result of a increasingly growing effort to meet the increasing demand in aircraft, space, defence and automotive applications for light weight, affordable, energy saving, rigid and strong materials. In this direction, aluminum matrix composites ( AMCs) are emerging as promising materials $[1,2,14]$. The addition of ceramic additives to the metal matrix enhances hardness and resistance to thermal shock[3]. The physical and mechanical strength of the material increases, but with the rise in the volume fraction of the $\mathrm{SiC}$ particles[4], the elongation decreases. $\mathrm{Al} 2 \mathrm{O} 3$ is one of the most commonly used reinforcement systems. But it has its own demerits, such as low aluminium wettability, and a greater percentage of weight contributes to increased porosity[5,14]. Boron carbide is a non-metallic reinforcement with high hardness combined with high wear resistance and high melting point, and due to the addition of chemicals, it has resistance to change. This gives high specific power, elastic modulus, strong wear resistance and thermal stability to the reinforcement of aluminum composites with B4C particles.[6] The wear studies on Al-B4C composites with a varying percentage of weight of $\mathrm{B} 4 \mathrm{C}$ show a linear increase in wear resistance with B4C content and the highest wear resistance was observed at 15 percent reinforcement of $\mathrm{B} 4 \mathrm{C}[7]$.Under extreme boundary lubrication conditions, the friction and wear behavior of MoS2, boric acid, graphite and $\mathrm{TiO} 2$ were compared. The results indicate that $\mathrm{MoS} 2$ and graphite were 30-50 percent more efficient than the other two lubricants. A decreasing trend with an increase in sliding speed due to increased temperature and greater shear force is shown by the friction coefficient. High 
friction coefficient values for all lubricants $(0.2$ to $0.5)$ have been reported. Under boundary lubrication conditions, this is due to prevailing solid interactions. For lubrication, boric acid and $\mathrm{TiO} 2$ were not very successful [8]. In cams, gears, bearings, clutches and other applications involving sliding contact or rolling contact [9], dry sliding metal-to - metal contact wear may be observed. The wear resistance depends heavily on the rotational velocity and hardness of the counter materials. Due to the reciprocal abrasion between the counter material and the wear surface of the specimen, the counter-face $b$ materials with a lower hardness have decreased the wear resistance [10]. Processing methods such as the method of stir casting have proven to be relatively costeffective and easy to use. In this paper [11], advances in mechanical and tribological properties were discussed. The Taguchi method is a powerful experimental design tool. It provides a easy, effective and systematic approach to cost and quality optimization [12]. To research the boron carburization and organization of AISI 1015 steel on tensile strength [13], Taguchi-grey relational analysis is used. These studies emphasise that improved tribological properties are provided by the use of multiple reinforcements in aluminum matrix hybrid composites. In parametric research on the tribological behavior of aluminum matrix hybrid composites, however, efforts are scarce. An attempt is made in this context to research the effect of graphite particles, load, percentage compliance, sliding speed and sliding distance on the tribological action of hybrid composites AlB4C-Gr and Al-B4C-MoS2.

\section{Materials and methods Materials Used}

The aluminum alloy 356 was used as the base alloy in this analysis. On the basis of mechanical properties and applications, materials have been chosen. It is, in practice, a high-strength casting alloy for general purposes. Table 1 presents the composition of 356 aluminum alloys used in this experimental work. As one of the reinforcement material, boron carbide (B4C) particles of average size63 microns were used. It has many attractive properties, such as low specific gravity, high hardness, high elastic module and absorption of neutrons, which help B4C to be widely used as cermets and armour materials. For nuclear applications, boron carbide is especially suitable. The morphology of B4C particles has been shown in Figure 1.

Table.1.Chemical composition of 356 aluminium alloy

\begin{tabular}{|c|c|c|c|c|c|c|c|c|c|}
\hline Constituent & $\mathrm{Cu}$ & $\mathrm{Si}$ & $\mathrm{Fe}$ & $\mathrm{Mg}$ & $\mathrm{Mn}$ & $\mathrm{Ti}$ & $\mathrm{Ni}$ & $\mathrm{Zn}$ & $\mathrm{Al}$ \\
\hline Weight $\%$ & 0.13 & 7.08 & 0.49 & 0.39 & 0.03 & 0.06 & 0.01 & 0.02 & Remainder \\
\hline
\end{tabular}

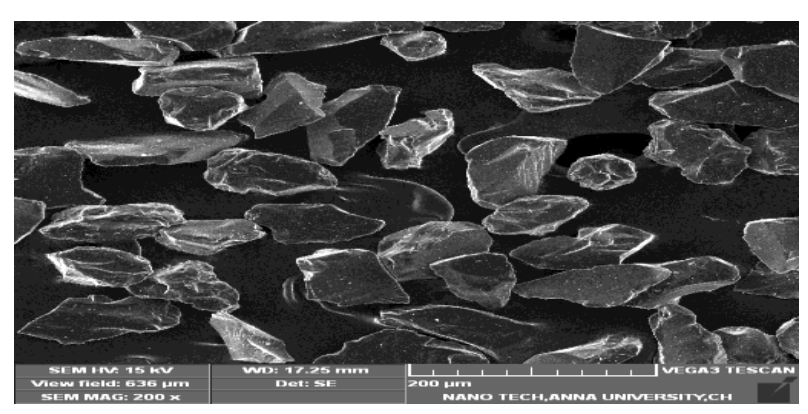

Fig.1 Morphology of B4C particles

In order to achieve enhanced friction and wear properties under conditions of intense pressures and/or temperatures, solid lubricants can be spread in water, oils, and greases. Graphite is one of the solid lubricants that has a layered, planar structure. There are somewhat close physical properties to the two known forms of graphite, alpha (hexagonal) and beta (rhombohedral). To its lower density, the layering leads. Graphite powders are valued for their self-lubricating properties and dry Lubricating properties in industrial applications. Graphite can provide up to $400^{\circ} \mathrm{C}$ of 
lubrication. Fabrication of Hybrid Composites The hybrid aluminum matrix composites have been produced using the Stir casting technique. The furnace casting setup for stir casting is shown in figure 2. The 356 aluminum alloy ingots were collected in a graphite crucible and melted in an electric furnace. It steadily increased the temperature to 850 o C. At 800 o C, the melt was degassed using a solid dry hexachloro ethane degasser (C2Cl6, 1 percent wt). For the creation of the three separate hybrid composites (356/6 percent B4C/2 percent Grand 356/6 percent B4C/ 2 percent MoS2), the molten metal was stirred to create a vortex and the preheated $(250 \mathrm{oC})$ boron carbide particles and Graphite and MoS2 (2 wt percent) were added. For 5 minutes, the slurry was stirred at $350 \mathrm{rpm}$. To the molten metal, potassium hexa flurotitanate (K2TiF6 1 percent wt) was applied. The aim of adding titanium to the $\mathrm{Al} /$ $\mathrm{B} 4 \mathrm{C}$ composite casting is to build a reaction layer on the interface containing titanium carbide (TiC) and titanium boride (TiB2) to improve wettability and interfacial bonding. Potassium $(\mathrm{K})$ and Fluoride $(\mathrm{F})$ lead to removing the oxide layer on the aluminum surface by incorporating Titanium (Ti) in the form of K2TiF6. The boron carbide percentage added was 6 percent by weight. The molten metal that was stirred was poured into preheated cast iron moulds $(650 \mathrm{o} \mathrm{C})$ and cooled to room temperature.

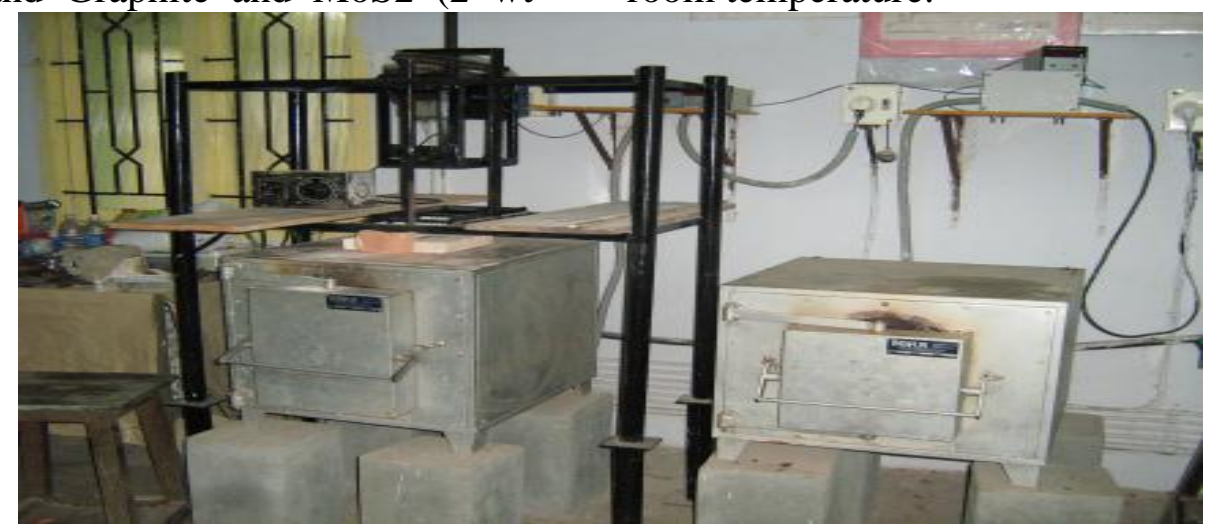

Fig. 2 Stir Casting Setup

\subsection{Wear Test}

The wear checks were carried out using a pin on the measuring machine for disc wear. The wear sample (pin) with a diameter of $6 \mathrm{~mm}$ and a height of $50 \mathrm{~mm}$ was machined from cast samples and then metallographic ally polished. In a single pan electronic weighing machine with a minimum count of $0.0001 \mathrm{~g}$, the initial weight of the sample was determined. By applying the load, the pin was pressed against the AISI 4140 steel disc with a hardness of 55HRC. The specimens were washed with acetone after running over a set sliding distance, dried and weighed to assess the weight loss due to wear. The weight loss is the difference in the weight measured before and after the wear Table 2 Process parameters and their Levels test of the composite sample, and then the wear rate, basic wear rate and friction coefficient were determined using the standard formulas.

\section{Design and Analysis of Experiments}

\section{Plan of Experiments}

In order to achieve minimum WR, SWR and COF, the experimental plan is designed to find the factors affecting the wear process. The experiments were built on the basis of an orthogonal array in order to relate the impact of the material's sliding speed, sliding distance, load and weight percentage reinforcement. Table 2 shows the process parameters and their levels.

\begin{tabular}{|l|l|l|l|l|}
\hline Level & $\begin{array}{l}\text { Sliding Speed, S } \\
(\mathbf{m} / \mathbf{s})\end{array}$ & $\begin{array}{l}\text { Sliding Distance, D } \\
(\mathbf{m})\end{array}$ & $\begin{array}{l}\text { Load, } \\
\mathbf{L}(\mathbf{N})\end{array}$ & $\begin{array}{l}\text { Reinforcement, } \\
\text { R (Wt\%) }\end{array}$ \\
\hline 1 & 1 & 500 & 15 & Gr 2\% (or) \\
\hline 2 & 1.5 & 1000 & 30 & $M_{2} 2 \%$ \\
\hline 3 & 2 & 1500 & 45 & \\
\hline
\end{tabular}




\subsection{Taguchi Design of Experiments}

One of the essential and effective statistical techniques to research the effect of several variables simultaneously is Design of Experiments. Compared to the complete factorial design of experiments, this approach significantly reduces the number of experiments needed to model the response function. The Taguchi technique is designed for process optimization and the optimal combination of factors for a given answer is defined. The ultimate goal of the approach is to manufacture low-cost goods of high quality. In Table 3, the L18 orthogonal array used for this work is shown.

Table $3 \quad \mathrm{~L}_{18}$ Orthogonal Array

\begin{tabular}{|c|c|c|c|c|}
\hline S.NO & Material & Speed & Distance & Load \\
\hline 1 & $\mathrm{Gr}$ & 1 & 500 & 15 \\
\hline 2 & $\mathrm{Gr}$ & 1 & 1000 & 30 \\
\hline 3 & $\mathrm{Gr}$ & 1 & 1500 & 45 \\
\hline 4 & $\mathrm{Gr}$ & 1.5 & 500 & 15 \\
\hline 5 & $\mathrm{Gr}$ & 1.5 & 1000 & 30 \\
\hline 6 & $\mathrm{Gr}$ & 1.5 & 1500 & 45 \\
\hline 7 & $\mathrm{Gr}$ & 2 & 500 & 30 \\
\hline 8 & $\mathrm{Gr}$ & 2 & 1000 & 45 \\
\hline 9 & $\mathrm{Gr}$ & 2 & 1500 & 15 \\
\hline 10 & $\mathrm{MoS}$ & 1 & 500 & 45 \\
\hline 11 & $\mathrm{MoS}_{2}$ & 1 & 1000 & 15 \\
\hline 12 & $\mathrm{MoS}_{2}$ & 1 & 1500 & 30 \\
\hline 13 & $\mathrm{MoS}_{2}$ & 1.5 & 500 & 30 \\
\hline 14 & $\mathrm{MoS}_{2}$ & 1.5 & 1000 & 45 \\
\hline 15 & $\mathrm{MoS}_{2}$ & 1.5 & 1500 & 15 \\
\hline 16 & $\mathrm{MoS}_{2}$ & 2 & 500 & 45 \\
\hline 17 & $\mathrm{MoS}_{2}$ & 2 & 1000 & 15 \\
\hline 18 & $\mathrm{MoS}_{2}$ & 2 & 1500 & 30 \\
\hline
\end{tabular}

\subsection{Grey Relational Analysis}

One of the important theories is the Grey theory, which can be used to evaluate complexity, multiinput and discrete data. Between black and white, a grey system has a degree of detail. The grey relational analysis is a measure of the absolute value of the discrepancy between sequences in the data and is often used for the calculation of the approximate correlation between sequences. It is an efficient means of evaluating the association with less data between the sequences and can evaluate several variables.

\subsection{Analysis approach}

Using 18 separate experiments, the experiments were performed according to Taguchi's L18orthogonal array. These 18 experiments, for GRA, became 18 subsystems. The effect of these subsystems was evaluated using GRA on the response variables. The wear tests (system) were evaluated by performing 9 experiments (subsystems) and each experiment was called a series of comparability. Minimum values of the wear rate, specific wear rate and coefficient of friction were given for parametric conditions corresponding to the highest weighted GRG. In this way, using the GRA method, the multiobjective problem was translated into single objective optimization.

\section{Results and discussion}

The wear tests were conducted to study the effect of process parameters on the characteristics of the output response. From experimental results, the GRG of the response characteristics for each variable at different levels was determined. The primary effects of GRG process variables have been plotted. The response graphs are used to analyse the parametric effects on the characteristics of the response. The GRG variance analysis (ANOVA) is performed to classify the significant variables and to measure their effects on the characteristics of the response. In terms of mean response characteristics, the most optimal 
www.rspsciencehub.com

settings of process variables are calculated by evaluating the response graphs and the ANOVA

Table 4 Experimental Results of Composites

\begin{tabular}{|c|c|c|c|c|c|c|c|}
\hline $\begin{array}{c}\text { S.N } \\
\mathbf{O}\end{array}$ & $\mathbf{C O F}$ & $\begin{array}{c}\text { WR } \\
\mathbf{3}\end{array}$ & $\begin{array}{c}\text { SWR* } \\
\mathbf{E - 3}\end{array}$ & $\begin{array}{c}\text { GRC } \\
\text { SWR }\end{array}$ & $\begin{array}{c}\text { GRC } \\
\text { WR }\end{array}$ & $\begin{array}{c}\text { GR } \\
\text { COF }\end{array}$ & $\begin{array}{c}\text { GR } \\
\text { GRADE }\end{array}$ \\
\hline 1 & 0.226 & 0.288 & 4.317 & 0.351 & 0.911 & 0.333 & 0.532 \\
\hline 2 & 0.169 & 0.156 & 4.676 & 0.333 & 0.965 & 0.456 & 0.585 \\
\hline 3 & 0.156 & 0.08 & 3.597 & 0.394 & 1 & 0.498 & 0.631 \\
\hline 4 & 0.115 & 0.197 & 2.95 & 0.442 & 0.947 & 0.701 & 0.697 \\
\hline 5 & 0.184 & 0.109 & 3.273 & 0.417 & 0.986 & 0.416 & 0.606 \\
\hline 6 & 0.161 & 0.097 & 4.348 & 0.35 & 0.992 & 0.481 & 0.608 \\
\hline 7 & 0.179 & 0.11 & 3.309 & 0.414 & 0.986 & 0.431 & 0.61 \\
\hline 8 & 0.182 & 0.092 & 4.137 & 0.361 & 0.994 & 0.421 & 0.592 \\
\hline 9 & 0.094 & 0.109 & 1.631 & 0.59 & 0.986 & 0.887 & 0.821 \\
\hline 10 & 0.147 & 0.083 & 3.741 & 0.385 & 0.998 & 0.532 & 0.638 \\
\hline 11 & 0.085 & 0.206 & 3.094 & 0.431 & 0.943 & 1 & 0.791 \\
\hline 12 & 0.113 & 0.133 & 3.981 & 0.37 & 0.975 & 0.715 & 0.687 \\
\hline 13 & 0.177 & 4.301 & 0.143 & 0.949 & 0.333 & 0.434 & 0.572 \\
\hline 14 & 0.162 & 3.226 & 0.072 & 0.977 & 0.402 & 0.478 & 0.619 \\
\hline 15 & 0.208 & 1.195 & 0.08 & 0.973 & 0.654 & 0.364 & 0.664 \\
\hline 16 & 0.187 & 0.717 & 0.016 & 1 & 0.768 & 0.409 & 0.726 \\
\hline 17 & 0.232 & 2.151 & 0.143 & 0.949 & 0.505 & 0.324 & 0.593 \\
\hline 18 & 0.169 & 2.389 & 0.08 & 0.973 & 0.478 & 0.456 & 0.636 \\
\hline & & & & & & & \\
\hline
\end{tabular}

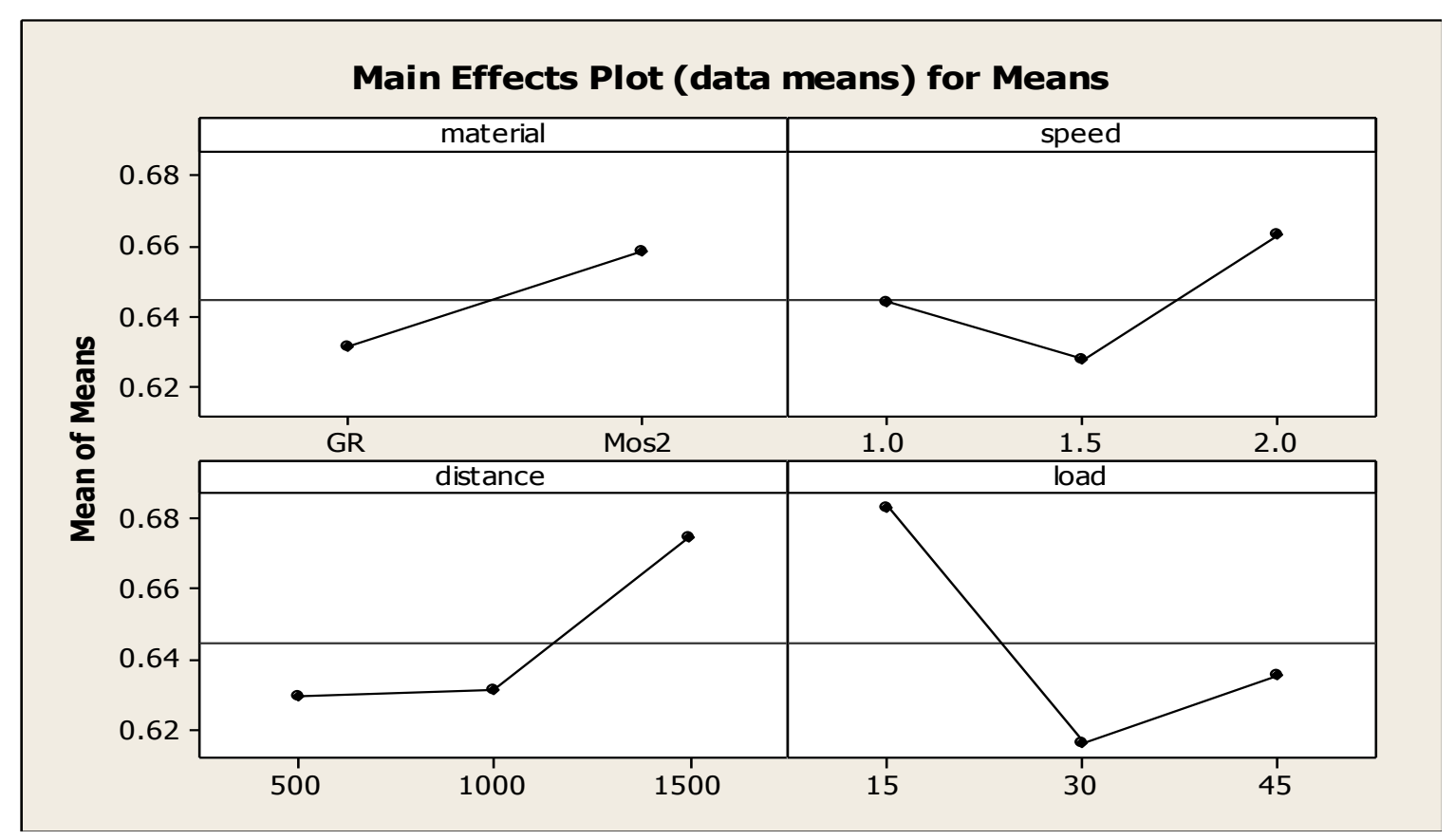

Fig.3 Response Graphs of 356/ $6 \% \mathrm{~B} 4 \mathrm{C} / 2 \% \mathrm{Gr}, 2 \% \mathrm{MoS}_{2}$ Composites 


\begin{tabular}{|c|c|c|c|c|}
\hline Level & Materials & Sliding Speed, $\mathbf{S}(\mathbf{m} / \mathbf{s})$ & Sliding Distance, D (m) & Load, L (N) \\
\hline 1 & 0.6313 & 0.6440 & 0.6292 & $\mathbf{0 . 6 8 3 0}$ \\
\hline 2 & $\mathbf{0 . 6 5 8 4}$ & 0.6277 & 0.6310 & 0.6160 \\
\hline 3 & & $\mathbf{0 . 6 6 3 0}$ & $\mathbf{0 . 6 7 4 5}$ & 0.6357 \\
\hline Delta & 0.0271 & 0.0353 & 0.0453 & 0.0670 \\
\hline Rank & 4 & 3 & 2 & 1 \\
\hline
\end{tabular}

All the designs, plots and analysis were performed using Minitab statistical software in this report. Figure 3 shows that the GRG increases with an increase in sliding speed, sliding distance and reinforcement, and decreases with an increase in load. The pin wears initially as the pin slides over the disc and then a mechanically mixed layer is created and this resists the composite pin wear rate. Table 5 shows the average of each response characteristic for each factor level. The table contains ranks that compare the relative magnitude of impact, based on delta statistics. For each element, the delta statistic is the maximum minus the lowest average. Based on delta values, ranks are allocated; rank 1 is assigned to the highest delta value, rank 2 is assigned to the second highest, and so on. The ranks display the relative significance of each factor to the answer.The ranks and delta values indicate that sliding distance has the greatest impact on GRG and is followed in that order by sliding speed, reinforcement percentage and load. It can be seen from Figure 3 that the maximum GRG is given by 2 sliding speed levels, 3 sliding distance levels, 1 load level and 2 reinforcement levels. Analysis of variance ( ANOVA) was conducted to research the importance of the process variables for GRG. We can see from ANOVA table 6 that sliding speed and sliding distance were most influential in achieving maximum GRG. Whereas on GRG, load and reinforcement have less value.

Table 6ANOVA of 356/ $6 \% \mathrm{~B} 4 \mathrm{C} / 2 \% \mathrm{Gr}, 2 \%$ MoS2 Composites

\begin{tabular}{|c|c|c|c|c|c|}
\hline Source & DOF & $\begin{array}{c}\text { Sequence } \\
\text { sum of } \\
\text { square }\end{array}$ & $\begin{array}{c}\text { Mean Sum of } \\
\text { Squares }\end{array}$ & F & Contribution \\
\hline Reinforcement & 1 & 0.003308 & 0.00331 & 21.83498 & $3.45 \%$ \\
\hline speed & 2 & 0.003752 & 0.00188 & 12.38284 & $3.91 \%$ \\
\hline distance & 2 & 0.007901 & 0.00395 & 26.07591 & $8.23 \%$ \\
\hline load & 2 & 0.014232 & 0.00712 & 46.9703 & $14.82 \%$ \\
\hline material*speed & 2 & 0.020556 & 0.01028 & 67.84158 & $21.41 \%$ \\
\hline $\begin{array}{c}\text { material*dista } \\
\text { nce }\end{array}$ & 2 & 0.006355 & 0.00318 & 20.9736 & $6.62 \%$ \\
\hline speed*distance & 4 & 0.039601 & 0.0099 & 65.34818 & $41.25 \%$ \\
\hline Residual Error & 2 & 0.000303 & 0.00015 & & $0.32 \%$ \\
\hline Total & 17 & 0.096008 & & & $100.00 \%$ \\
\hline
\end{tabular}

\subsection{Confirmation Experiment:}

For the determination of the optimum conditions, experimental findings are analysed. The variables at levels M2, S3, D3 and L1 that are sliding velocity $2 \mathrm{~m} / \mathrm{s}$, sliding distance $1500 \mathrm{~m}$, load 15 $\mathrm{N}$ and 2 percent MoS2 reinforcement are the 


\section{www.rspsciencehub.com}

optimal parameters for obtaining minimum wear rate, basic wear rate and friction coefficient from Figure 3 and response Table 5. Using Taguchi Design of Experiments, the optimum parameters are used for performing the confirmation experiment and also for predicting the wear rate, basic wear rate and friction coefficient. The forecast GRG value is 0.744 and the experimental GRG value is 0.734 , which is similar to the forecast values. So the technique of optimization holds good for this work of research.

\section{Conclusion}

It is possible to draw the following inference from the study of the tribological behaviour of these composites.

(1) Sliding distance is the parameter that has the largest statistical effect on the GRG values of the sliding velocity and sliding distance values of composites $(41.25 \%)$, followed by the values of materials and sliding distance $(21.41 \%)$ and load (14.82\%).

(2) Optimum sliding speed values are $1.5 \mathrm{~m} / \mathrm{s}$, sliding distance is $1500 \mathrm{~m}$, load is 15 and 2 percent MoS2added hybrid composites are reinforcements.

(3) 356/6 percent $\mathrm{B} 4 \mathrm{C} / 2$ percent $\mathrm{MoS} 2$ composites are greater than $356 / 6$ percent $\mathrm{B} 4 \mathrm{C} / 2$ percent $\mathrm{Gr}$ composites with tribological characteristics.

(4) B4C increases material hardness. The mach inability is improved by MoS2.

\section{References}

[1].Wang DZ, Peng HX, Liu J, Yao C K. Wear Behaviour And Microstructural Changes of $\mathrm{SiCw}-\mathrm{Al}$ Composite Under Unlubricated Sliding Friction. Wear 1995;184:187-92.

[2].Garcia-Cordovilla C, Narciso J, Louis E. Abrasive Wear Resistance of Aluminium Alloy/Ceramic Particulate Composites. Wear 1996;192:170-7.

[3].Liang Y H, Wang H Y, Yang Y F, Wang Y Y, Jiang Q C. Evolution Process of The Synthesis of Tic in The $\mathrm{Cu}-\mathrm{Tic}-\mathrm{C}$ System [J]. Journal of Alloy of Compounds, 2008, 452: 298-303.

[4]. Thakur S K, Kwee G T, Gupta M. Development And Characterization of Magnesium Composites Containing NanoSized Silicon Carbide And Carbon Nanotubes As Hybrid Reinforcements [J]. Journal of Material Science, 2007, 42: 10040-10046.
Volume 02 Issue 11 November 2020

[5].A.V Smith. Titanium Di Boride ParticleReinforced Aluminium With High Wear Resistance. Composite materials research Laboratory, State university of New York, USA.

[6].Rohatgi P.K , Guo R Q , Huang P \&Ray S. Friction and Abrasion Resistance of Cast Aluminium Alloy-Flyash Composites. Met.Mat.Transactions A, 28(1997) 245-250.

[7].Mohammad S E et al. Fabrication and Evalution of Mechanical and Tribological Properties of Boron Carbides Reinforced Aluminium Matrix Nano Composites. Journal material design, 38(2009), 1894-1898.

[8].Rohatgi PK, Guo R, Kim JK, Rao S, Stephenson T, Waner T. Wear and friction of cast Al-SiC-Gr composites. In: Proceedings of materials solutions'97 on wear of engineering materials, Indianapolis, Indiana; 15-18, 1997, p. 205-11(September).

[9].Ted Guo ML, Tsao CYA. Tribological Behavior of Self-Lubricating Aluminium/ SiC/ Graphite Hybrid Composites Synthesized by the Semi-Solid Powder Densification Method. Compos Sci Technol 2000;60:65-74.

[10].Riahi AR, Alpas AT. The Role of TriboLayers on the Sliding Wear Behavior of Graphitic Aluminum Matrix Composites. Wear 2001;251:1396-407.

[11].Basavarajappa S, Chandramohan G, Mahadevan Arjun, Tangavelu Mukundan, Subramanian R, Gopalakrishnan P. Influence of Sliding Speed on the Dry Sliding Wear Behaviour And The Subsurface Deformation On Hybrid Metal Matrix Composite. Wear 2007;262:1007-12.

[12].Ross P J. Taguchi technique for quality engineering $[\mathrm{M}]$. New York: McGraw-Hill, 1988.

[13].Mathew $\mathrm{M}, \quad$ Rajendrakumar $\mathrm{P} \quad \mathrm{K}$. Optimization Of Process Parameters of BoronCarburized Low Carbon Steel for Tensile Strength by Taquchi Method With Grey Relational Analysis [J]. Materials \& Design, 2011,32:3637_3644.

[14].J.Udaya Prakash, T.V.Moorthy, S.Ananth . Fabrication and Sliding Wear Behaviour of Metal Matrix Composites. Applied Mechanics and Materials Vol. 612 (2014) pp 157-162. 